\title{
Impact of ZnO Nano Materials on Medicinal Black Rice Seed Germination
}

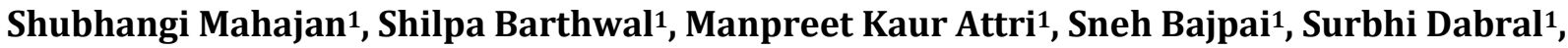 \\ Manika Khanuja ${ }^{2}$, Ajit Varma ${ }^{*}$
}

${ }^{1}$ Amity Institute of Microbial Technology, Amity University, Noida, India

${ }^{2}$ Centre for Nanoscience and Nanotechnology, Jamia Millia Islamia, New Delhi, India

Email: *ajitvarma@amity.edu

How to cite this paper: Mahajan, S., Barthwal, S., Attri, M.K., Bajpai, S., Dabral, S., Khanuja, M. and Varma, A. (2019) Impact of ZnO Nano Materials on Medicinal Black Rice Seed Germination. Journal of Minerals and Materials Characterization and Engineering, 7, 180-192.

https://doi.org/10.4236/jmmce.2019.74014

Received: April 26, 2019

Accepted: July 28, 2019

Published: July 31, 2019

Copyright $\odot 2019$ by author(s) and Scientific Research Publishing Inc. This work is licensed under the Creative Commons Attribution International License (CC BY 4.0).

http://creativecommons.org/licenses/by/4.0/

\section{c) (i) Open Access}

\begin{abstract}
Black rice Oryza sativa is primarily grown in East and North East of India. This variety could not become popular due to low yield and being expensive. It is rich in three kinds of Anthocyanin contents which exhibit great impact on human health. Four different kinds of $\mathrm{ZnO}$ nanomaterial were prepared at variable temperature ranging from $250^{\circ} \mathrm{C}$ to $500^{\circ} \mathrm{C}$. The Interaction of black rice grain with nanozinc material leads to the observation that seeds germinated early. Rooting development was higher. Better effects were observed while those interacted with nanomaterial prepared at $350^{\circ} \mathrm{C}$. In the present study the aim was to enhance the yield and value addition. To best of our knowledge this is the first scientific attempt [see also patent filed Varma et al. 2019]. The mechanism involved needs further elaborate elucidation. We hope that the goal can also be achieved by interaction of seeds with mycosymbiont-Piriformospora indica (Serendipita indica) a potent cultivable mycorrhiza. The precise objective of this communication is to illustrate the interaction of black rice seed with several synthesized nano zinc material which varied in shape, size and diameter.
\end{abstract}

\section{Keywords}

Black Rice (Oryza sativa), Zinc Nanomaterials, Piriformospora indica (Serendipita indica), Anthocyanin

\section{Introduction}

Rice is indeed the staple diet for a vast majority of Indians inhabiting the 15 agro-climatic regions and is a source of nutritional supplement to the poorest of the poor. However, its ability to foster the nutritional needs of the marginalized populace has not been successfully harnessed to its fruition. Black Rice was originally cultivated in Odisha (East India) but is presently extensively cultivated 
in North-Eastern States of India such as Assam and Manipur [1], where despite its low yield, it is consumed for its medicinal value [2]. Black rice includes several varieties with a long history of cultivation in Southeast Asian countries such as China, India and Thailand. There are more than 200 types of black rice varieties in the world. Only China is responsible for $62 \%$ of global production of black rice and it has developed more than 54 modern black rice varieties with high yield characteristics and multiple resistances. China cultivates the maximum varieties of black rice followed by Sri Lanka, Indonesia, India and Philippines etc. Thailand occupies the ninth position to black rice cultivation. Interest in black rice is indicated by the number of accessions held in germplasm collections, e.g. China-359, Sri Lanka-50, Indonesia-42, India-30, the Philippines-25 and Bangladesh-24 [3].

Black rice or kings rice is a rare range of rice types of the species Oryza sativa L., which is a medium-grain, non-glutinous heirloom rice. Some species of black rice are glutinous also, for example, Thai black rice, has a sticky texture and is often used in desserts in Thai cuisine. Glutinous black rice has higher amounts of amylopectin, which have some benefits when taken in balanced amount.

Nano science coupled with nano technology is one of the most important emerging tools which can complement modern agriculture by providing sufficient amounts of agro-chemicals and new delivery mechanism to improve crop productivity. Nano materials control the uptake and release of essential nutrients. This science promises to accelerate the development of biomass to fuel production technologies. Potential benefits of nano technology for agriculture need to be balanced for substratum, water and environment. Nano particles ranging from 1 - $100 \mathrm{~nm}$ have unique physical and chemical properties i.e., high surface areas, high reactivity, to enable pore size, and particle morphology; therefore they have novel applications in diverse fields of science. There is growing pressure on agricultural resources throughout the world due to pressure from human population. The green revolution introduced in 1970 solved the problem of hunger, by and large in many developing countries. Since then the global human population has doubled and stagnation in agricultural productivity has been experienced in many food crops. This has necessitated the need of innovative technologies for crop improvement and resource conservation. The nano technology is one of the recent innovative sciences that has tremendous potential to enhance the agriculture, horticulture, viticulture and allied fields.

One serving of black rice contains around 156 calories, in addition to high levels of flavonoid phytonutrient anthocyanin, it is a good source of fiber as well as micro-nutrients such as iron and copper, along with plant based protein [4].

The black rice is fortified with phytonutrients such as anthocyanin. Rich in fibers suggests that local inhabitants of the North-eastern parts of the country consume it to reduce not only the burden of free radicals in their body but also ease out the bowel movements thereby preventing episodes of bloating, diarrhea as well as constipation. Another important trait of black rice pertains to its unique ability to detoxify the body leading to weight loss. Black rice is gluten free and can also be 
used as a staple diet for patients suffering from Celiac Disease, can supplement their diet with black rice to fulfill their daily requirement of protein and fiber.

\subsection{Types of Anthocyanin Present in Black Rice}

Black rice reflected three different types of pigments upon experimentation performed by employing HPLC. Out of three pigments detected, one was characterized as cyanidin-3-glucoside (C3G) and another was identified as cyanidin-fructoside [5]. Cyanidins are a sub-category of the dark pigments [Figure 1]. It can be seen as the most pharmaceutically effective anthocyanin subcomponent as they seem to have the greatest uptake rate, the least decay, and the most clinical significance out of all anthocyanins. It has various effects in cells, most of which can be described as being anti-diabetic and possibly slightly benefit other parameters associated with "metabolic syndrome" (anti-inflammatory, anti-oxidant, etc.) [6].

Cyanidin-3-glucoside (C3G)

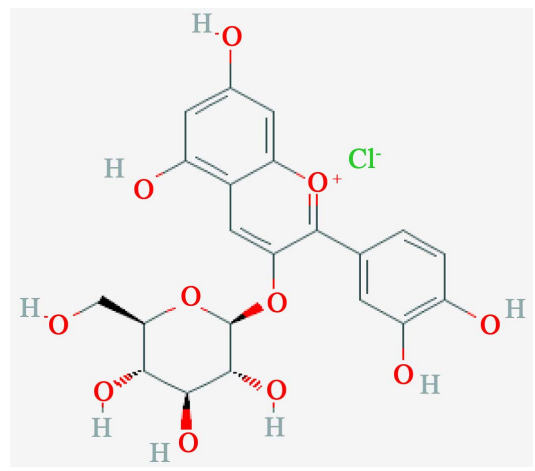

Figure 1. Chemical structure of Cyanidin-3-glucoside.

\section{Malvidin 3-glucoside}

Malvidin is an anthocyanidin. As a primary plant pigment, its glycosides are highly abundant in nature. Slightly acidic and neutral solutions of Maldivian are characteristically of a red color, while basic solutions of Maldivian yield a blue color [Figure 2].

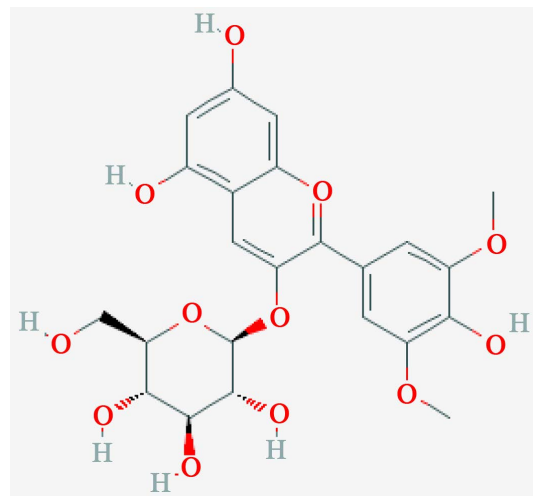

Figure 2. Chemical structure of Malvidin 3-glucoside. 
Malvidin 3-glucoside is found in alcoholic beverages. Malvidin 3-glucoside is a pigment of skins of black grapes, also in other plants. Malvidin 3-glucoside is found in red wine [7].

\section{Peonidin-3-glucoside}

Peonidin is an anthocyanidin and a primary plant pigment. Peonidin gives purplish-red hues to flowers such as the peony, from which it takes its name, and roses. It is also present in some blue flowers, such as the morning glory [Figure 3].

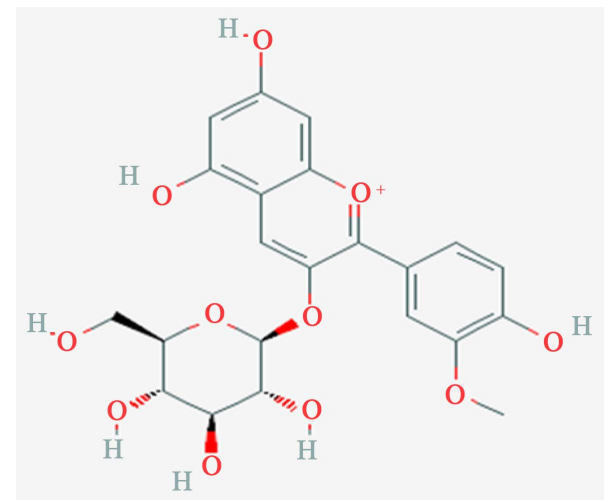

Figure 3. Chemical structure of Peonidin-3-glucoside.

Like most anthocyanidins it is $\mathrm{pH}$ sensitive, and changes from red to blue as $\mathrm{pH}$ rises. This happens because anthocynaidins are highly conjugated chromophores. When the $\mathrm{pH}$ is changed, the extent of the conjugation (of the double bonds) is altered, which alters the wavelength of light energy absorbed by the molecule [8]. It has a role as an antioxidant and a plant metabolite. It is an anthocyanin cation, a beta-D-glucoside and a monosaccharide derivative. It derives from a peonidin [9].

\subsection{Comparison of Nutritional Properties of Black Rice versus Brown and Wild Rice}

Cultivated rice, which includes black and brown varieties, are all said to originate from the genus Oryza over 10,000 years ago. Wild rice is in fact wild, typically growing in shallow water in small lakes or slow-flowing streams. But it's actually not rice! Wild rice is technically a grain from a reed-like aquatic plant (Zizania palustris), which is not related to rice. Black and brown rice have a similar consistency and nutty flavor. Wild rice also has a nutty taste, but it has a chewy outer layer and the grain on the inside has a somewhat vegetal flavor. The different types of rice differ in terms of nutrient content when we compare a $1 / 4$ cup cooked serving [10]:

- Black rice (gram):

$\diamond 4$ protein

$\diamond 32$ carbohydrates

$\diamond 2.3$ fiber 
0.8 sugars

$\diamond 0.7$ milligram iron

$\diamond$ Highest amount of antioxidants of any rice variety

- Wild rice (gram):

$\diamond 1.6$ protein

$\diamond 9$ carbohydrates

$\diamond 0.7$ fiber

$\diamond 0.3$ sugars

$\diamond 1$ milligram calcium

$\diamond 0.3$ milligram iron

- Brown rice (gram):

$\diamond 1.9$ protein

$\diamond 19.5$ carbohydrates

$\diamond$ fiber

$\diamond$ 0sugars

$\diamond 11$ calcium

$\diamond 0.4$ milligram iron

\section{Medicinal Value:}

Black rice is a rich source of phytonutrients, which works as a natural detoxifier and pulls out disease causing free radicals from the body.

Black rice is a great source of fiber, which helps in easing out the bowel movements, relieves bloating, diarrhea and prevents constipation. The soluble fiber of black rice binds with the toxins and effectively pulls out the waste from the body. This further leads to weight loss.

The bran hull of black rice, which is the outermost layer of the rice grain, contains one of the highest levels of the antioxidants-anthocyanin. The anthocyanin content of black rice is higher than any other grain, including brown rice, red rice, red quinoa, or other colored whole grain varieties.

Consuming the black rice can help to detoxify the body and cleanse the liver of harmful toxic build-up.

It reduces this oxidative stress and maintains healthy brain functioning.

$>$ It further improves learning and memory functioning those suffering from an estrogen deficit.

Black rice is completely free of gluten. So, people who are sensitive to gluten and/or are suffering from Celiac Disease (confirmed allergy to gluten) can add black rice to their daily diet to fulfill their daily requirement of protein and fiber.

The anthocyanins can treat effectively the asthma patients, by reducing the inflammation in the airways and mucus hypersecretion associated with this respiratory disorder.

> The anthocyanins have long been known to improve eyesight, reduce the retinal damage caused by a fluorescent light.

Anthocyanins, protects the body from free-radical damage which can lead to 
cancer.

Uniqueness of the Novel (Nano Zinc Enabled Phosphorus Ameliorated) Black Rice Fortified Food Targeting Micro- and Macro-Nutritional Deficiencies In Malnourished Children:

- Black Rice fortified with anthocyanins and soluble fiber detoxifies and cleanses the human body apart from preventing episodes of bloating, diarrhea as well as constipation can seriously address the malnourishment issues in children, pregnant women and elderly.

- The fact Black Rice is gluten free and fortified with fibers is a boon for the management if diets for patients afflicted with Celiac Disease and Diabetes, who are burdened with different types of digestive problems.

- Another important trait of black rice pertains to its unique ability to detoxify the body leading to weight loss. Black rice is gluten free and can also be used as a staple diet for patients suffering from Celiac Disease can supplement their diet with black rice to fulfill their daily requirement of protein and fiber.

- Fortification of Black Rice with essential micronutrients Zinc and Phosphorus could significantly improve the growth patterns as well as Neuro-behavioural disturbances exhibited in malnourished children burdened with these deficiencies apart from significantly improving the crop yields [11].

\subsection{Zinc Nanomaterials}

Zinc is known to play a critical role in normal functioning of body and is integrated with several enzyme systems. Adequate dietary intake of zinc has been shown to exert ameliorating effect on the skin, and this attenuates the likelihood of restricted linear growth in young children [12] [13]. Neuro-behavioral disturbances among infants and repeated infections are common among zinc-deficient subjects of all ages. Pregnant women with zinc deficiency are at the risk of complicated pregnancy outcomes. This is further complicated by the fact that Zinc deficiency is one of the major factors limiting the yield of agricultural crops. This necessitated he need to fortify black rice with zinc using zinc oxide nanoparticles [14]. It is believed that black rice augmented with zinc would not only ameliorate the health of the marginalized sections of the Indian populace but pave the way to improve the agricultural yield thereby sustainably improving the carrying capacity of the arable and [15].

The precise objective of this communication is the application of zinc nanomaterials to enhance the yield, value addition to active ingredients and health supplements for economically weak society. [Figure 4] depicts a pictorial view of Rice grains with and without husk. On boiling in water, the dark blackish red anthocynanins pigment oozed out as supernatant [Figure 5].

\section{Methods}

\subsection{Synthesis of Nano Zinc Materials}

$\mathrm{ZnO}$ nanorods were prepared by a mechanical-assisted thermal decomposition 

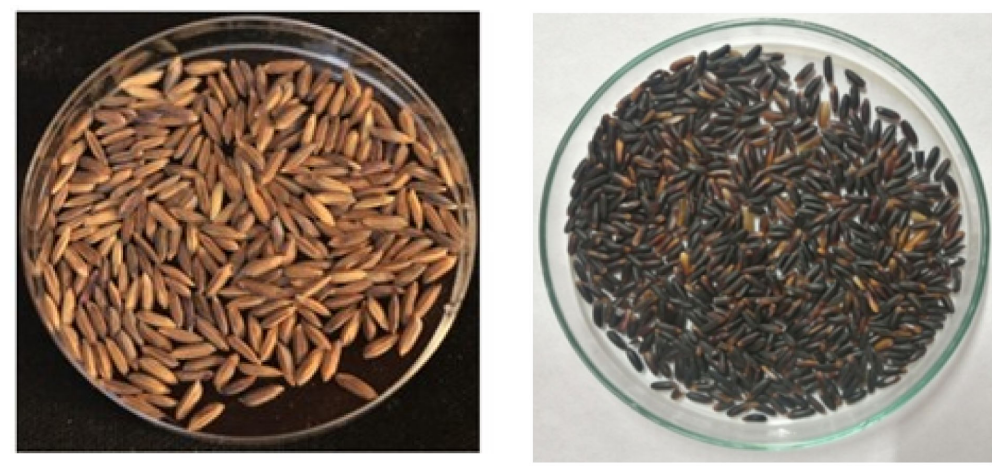

Figure 4. Black rice seeds with husk (left) and without husk (right).
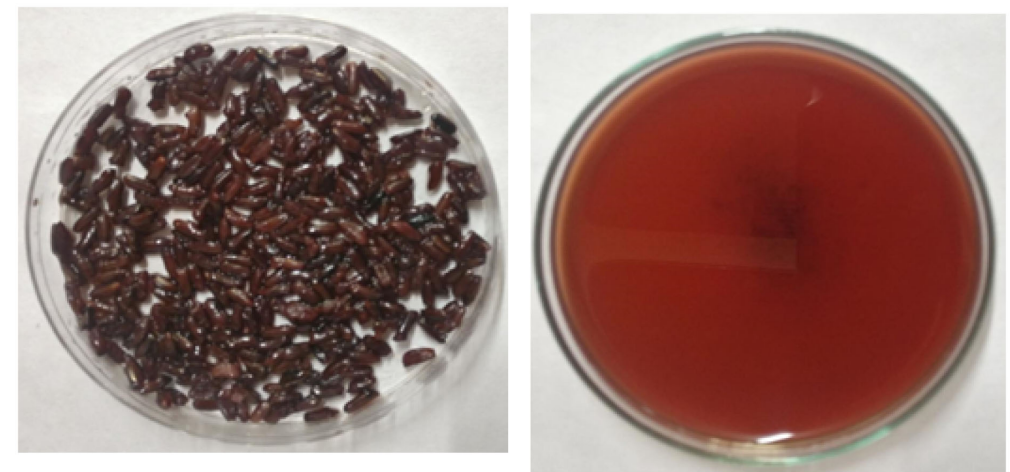

Figure 5. Boiled rice (left) and rice extract-mixture of anthocyanins (right).

process. Zinc acetate dihydrate $\left[\mathrm{Zn}\left(\mathrm{CH}_{3} \mathrm{COO}\right)_{22} \mathrm{H}_{2} \mathrm{O}\right]$ was used as precursor for synthesis of zinc oxide nanorods. In the synthesis process, zinc acetate dihydrate $(5 \mathrm{~g})$ was ground in a mortar and pestle for $45 \mathrm{~min}$ then loaded into an alumina crucible, which was then heated in a programmable muffle furnace (at ramp rate of $\left.4^{\circ} \mathrm{C} / \mathrm{min}\right)$ at different temperatures $\left(275^{\circ} \mathrm{C}, 350^{\circ} \mathrm{C}, 425^{\circ} \mathrm{C}\right.$, and $\left.500^{\circ} \mathrm{C}\right)$ for $4 \mathrm{~h}$ to obtain four $\mathrm{ZnO}$ nanopowders with different aspect ratios [16] [17]. The obtained powders were then washed twice with distilled water, followed by drying in an oven at $80^{\circ} \mathrm{C}$ for 8 hours.

The interaction of seeds with nano material was done in four replications and 4 independent experiments were performed.

\subsection{Characterization}

The nanoparticles were spherical, oblong and rod in shape [Figure 6]. The diameter varied from 9.6 - $25.5 \mathrm{~nm}$ in size. Table 1 indicates Zeta Potential at different temperatures. This varied from $-0.455,-2.50,-2.50$ and -6.51 .

\subsection{Interaction of Seeds with Nanomaterials}

For the present work, the authors have chosen the black rice variety-Chakhao Poireiton obtained from Manipur, North-east India [Figure 7]. The yield of black rice is extremely low, hence commercially not viable. Our attempt was to secure the early seed germination and enhance the yield [18] [19]. 

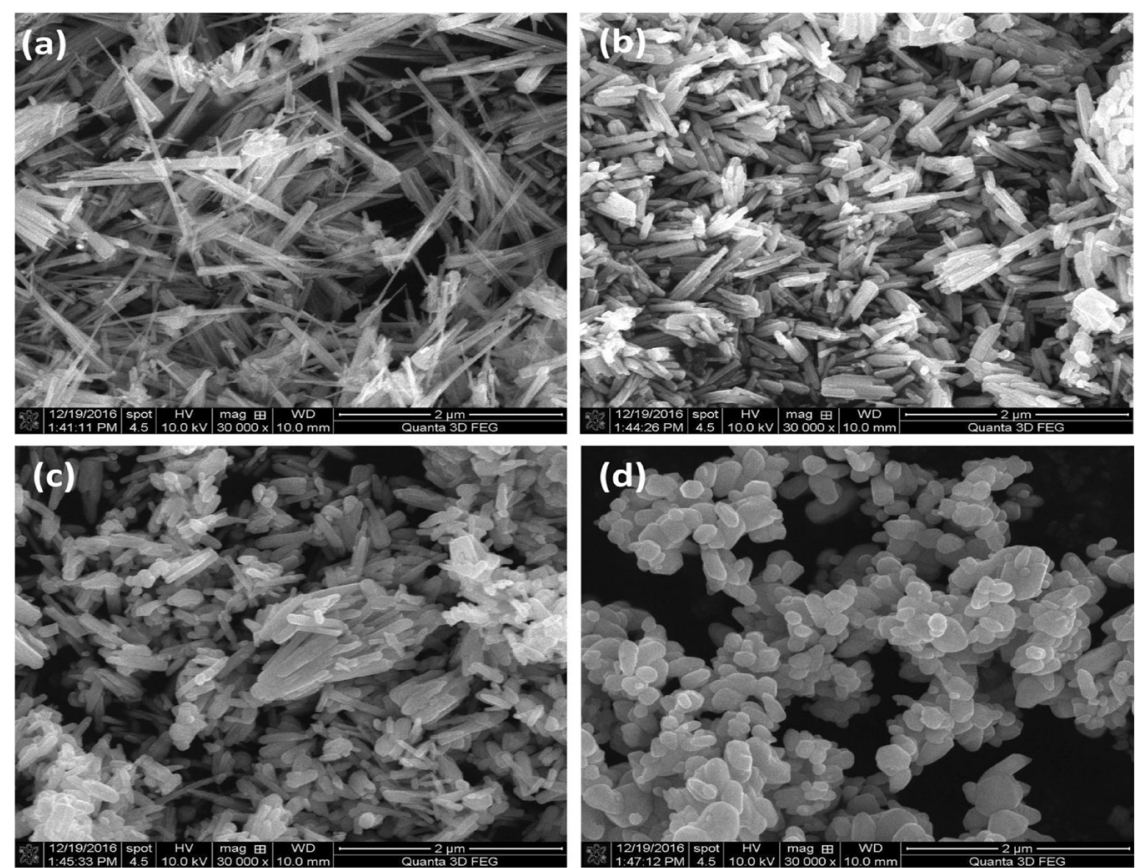

Figure 6. Scanning electron micrographs of (a) $\mathrm{ZnO}\left(275^{\circ} \mathrm{C}\right)$; (b) $\mathrm{ZnO}\left(350^{\circ} \mathrm{C}\right)$; (c) $\mathrm{ZnO}$ $\left(425^{\circ} \mathrm{C}\right)$ and $(\mathrm{d})\left(500^{\circ} \mathrm{C}\right)$ (reproduced with permission from ref. [21]).
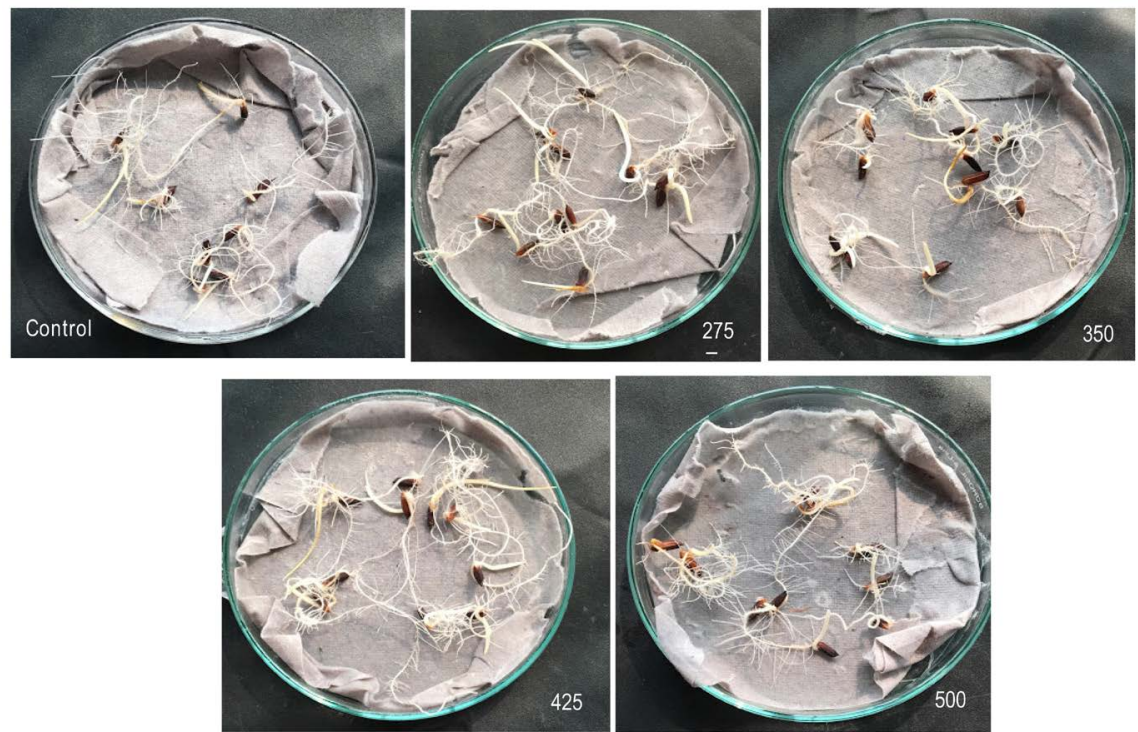

Figure 7. Seed germination on treatment with Zinc nanomaterials.

Table 1. Characterization of $\mathrm{ZnO}$-Zeta potential.

\begin{tabular}{cc}
\hline Samples & Zeta Potential \\
\hline $\mathrm{ZnO}\left(275^{\circ} \mathrm{C}\right)$ & -0.455 \\
$\mathrm{ZnO}\left(300^{\circ} \mathrm{C}\right)$ & -2.50 \\
$\mathrm{ZnO}\left(425^{\circ} \mathrm{C}\right)$ & -2.50 \\
$\mathrm{ZnO}\left(500^{\circ} \mathrm{C}\right)$ & -6.51
\end{tabular}


The seeds were germinated on the wet filter paper impregnated with $250 \mathrm{mi}-$ cro liter of $100 \mathrm{ppm}$ nano material prepared at different temperatures $\left(275^{\circ} \mathrm{C}\right.$, $350^{\circ} \mathrm{C}, 425^{\circ} \mathrm{C}$ and $500^{\circ} \mathrm{C}$ ). The glass petri plates were incubated in dark for five days at $25^{\circ} \mathrm{C}$.

\subsection{Confocal Based Analysis of $P$. indica Spores}

The methodology for isolating $P$. indica spores was adopted from Hilbert et al. (2013) with slight modifications. $0.002 \%$ of freshly prepared Tween 20 solution was autoclaved and stored at $4^{\circ} \mathrm{C}, 1 \mathrm{ml}$ of the solution was added to the $P$. indica culture plate and spores were scraped out with the help of spreader and collected in $2 \mathrm{ml}$ micro centrifuge tubes followed by centrifugation at $5000 \mathrm{~g}$ for $15 \mathrm{mi}$ nutes. The pellet was collected and mixed with $1 \mathrm{ml}$ autoclaved distilled water while the supernatant was discarded. Spores collected were stained with WGA-Alexa 488 conjugated dye (Invitrogen). Approximately $5 \mu \mathrm{l}$ of the dye (10 $\mu \mathrm{g} / \mathrm{ml}$ concentration) was used for staining $500 \mu \mathrm{l}$ of spores and were subjected to confocal microscopy. The images were captured using confocal microscope (Model: Nikon A1) under magnification of $40 \times$ at Amity Institute of Microbial Technology, Amity University, India. The confocal settings for WGA-Alexa 488 conjugated dye is as follows; excitation-488 nm, emission-515 [20].

\section{Results and Discussion}

Table 2 indicates the average number of root branches and root length measured after 5 days incubation. The maximum number of root branches and root length were recorded for those treated with nanozinc material synthesized at $350^{\circ} \mathrm{C}$. Early seed germination was also recorded while fortified with nano material. The preliminary work justifies the impact of nano zinc on seed germination and root development. This will help us to monitor the plant development [21] [22] [23]. When the nanoparticles penetrate into the plant, then it moves through tissues by two ways: the apoplast and the symplast. Apoplastic transport takes place outside the plasma membrane through the extracellular spaces, cell walls of adjacent cells and xylem vessels, whereas symplastic transport involves movement of water and minerals between the cytoplasm of adjacent cells through specialized structures called plasmodesmata and sieve plates. The apoplastic pathway is important for radial movement within plant tissues,

Table 2. Average number of root branches and root length.

\begin{tabular}{ccc}
\hline $\begin{array}{c}\text { ZnO synthesized at } \\
\text { variable temperature }\left({ }^{\circ} \mathrm{C}\right)\end{array}$ & $\begin{array}{c}\text { Average no. of } \\
\text { root branches }\end{array}$ & Root length $(\mathrm{cm})$ \\
\hline Control (no addition) & 1.1 & 4.9 \\
275 & 1.8 & 4.5 \\
350 & 3.3 & 6.2 \\
425 & 3.1 & 5.5 \\
500 & 2.6 & 6.1 \\
\hline
\end{tabular}


and allows nanomaterials to reach the vascular tissues. Once inside the central cylinder, nanoparticles can move toward the aerial parts through the xylem, following the transpiration stream. Nevertheless, reaching the xylem through the root implies crossing a barrier to the apoplastic pathway via endodermal cells. Another important symplastic transport is possible too, using the sieve tube. Our interpretation is in line with that reported by Pérez-de-Luque (2017) [24]. To authors best knowledge the interaction of $\mathrm{ZnO}$ with Black rice is the first report of its kind.

Lots of work has been done in biological system to address a wide range of field problems utilizing nanomaterials and nanodevices [25]. Elucidated various nanotechnological approaches especially in the field of agriculture including nano-polymer for seed hardening, nano-sensors, nano-barcodes and use of magnetic nanoparticles for aerial seeding. Sridhar (2012) [26] further established the use of metal oxide nano-particles in improving germination up to 30 per cent in aged seeds of black gram and tomato, respectively which could be probably due to the quenching of reactive oxygen species (ROS) generated during seed storage. Applications of nanotechnology in improving seed germination, emergence and growth of seedlings, thwarting pest attack [Nair et al., 27] and for early pathogen detection are few of the multifarious beneficial interventions in the field of agriculture. Hence the present investigation was made to study the effect of $\mathrm{ZnO}$ [28].

A study was conducted to evaluate the effects of Nano-Silicon (N-Si) for ameliorating negative effects of salinity on germination and growth of tomato seeds. $\mathrm{N}$-Si at 2 concentrations ( 1 and $2 \mathrm{mM}$ ) and $\mathrm{NaCl}(1$ and $2 \mathrm{mM})$ was studied on tomato seed germination. Results showed the great effects of N-Si to improve salinity stress on tomato seed germination. One mM N-Si under $25 \mathrm{mM}$ showed the great enhancement on germination characteristics such as germination rate, root length and dry weight [29].

Novel nanotool called "nano-embedded fungus" formed by impact of synergistic association of $\mathrm{ZnO}$-nanorods and fungus Piriformospora indica DSM 11827, for growth of Brassica oleracea var. botrytis (Broccoli) is reported. Enhancement in B. oleracea var. botrytis is reported on treatment with Nano embedded fungus. This is the first holistic study focusing on the impact of $\mathrm{ZnO}$-nanorods in the enhancement of fungal symbiont for enhanced biomass productivity of $B$. oleracea plant [30].

\section{Conclusions and Future Prospects}

The interaction of nano material with seedlings considerably enhanced the rooting pattern when incubated at $26^{\circ} \mathrm{C}$. The nanomaterials produced are more angular and pointed and it seems that they enter the root tissues much faster and influence the impact. More essential nutrient transport obviously alters the meta-geno-bolomics. At the moment we do not know the exact mechanism for spurt in rooting pattern due to interaction. It will be our future endeavour and research plan. 


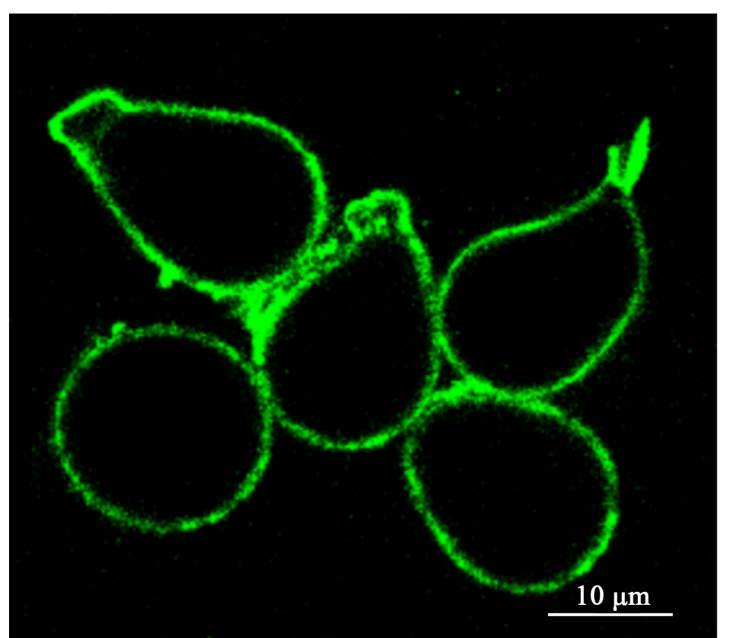

Figure 8. Image of Piriformospra indica (Serendipita indica) as observed under confocal microscope (stained with WGA dye-Wheat germ agglutinin). Model Nikon confocal A1 microscope.

Piriformospora indica was obtained from the rhizospheric soils of the woody shrubs Prosopis juliflora (Swartz) D.C. and Zizyphus nummularia (Burm. Fil.) Wt. \& Arn., screened from sandy desert soils of Rajasthan, Western India [31] [32]. The fungus is easily cultivable, lacks host specificity and colonizes roots of many different plants, mostly in an endophytic fashion. The original name was Piriformospora indica; however, in a recent Tansley Review New Phytologist, German and French scientists renamed the fungus as Serendipita indica [33] [Figure 8].

The fungus possesses unique property for plant promotion, early flowering and fruiting, and in addition, caters the value addition to the plant whereby secondary metabolites are enhanced. The fungus also helps in transportation of nutrients from soil to the plants. It has multi-functional properties and interacts with bacteria, algae and other fungi. The biotechnological applications are enormous.

\section{Acknowledgements}

Seed variety Chakhao Poireiton was obtained with the courtesy of Dr. Birjesh Sinha, Imphal, North-East India. Authors are thankful to National Funds, ICAR and DST, Nanomission, New Delhi, for partial funding. Authors are thankful to DST-FIST for providing Confocal microscope.

\section{Conflicts of Interest}

The authors declare no conflicts of interest regarding the publication of this paper.

\section{References}

[1] Anupam, C. (2015) Black Beauty. 
https://www.downtoearth.org.in/news/food/black-beauty-52195

[2] Annie, P. (2019) Black Rice Nutrition: What You Need to Know about "Forbidden Rice". https://draxe.com/black-rice-nutrition-forbidden-rice-benefits

[3] Ujjawal, K. (2016) Black Rice. Springer, Berlin.

[4] Bernice, C. (2016) Molecular Basis of Nutrition and Aging Science Direct. https://www.sciencedirect.com/topics/agricultural-and-biological-sciences/black-ric e

[5] Min-Kyoung, K., Han-ah, K., Kwangoh, K., et al. (2008) Identification and Quantification of Anthocyanin Pigments in Colored Rice. Nutrition Research and Practice, 2, 46-49. https://doi.org/10.4162/nrp.2008.2.1.46

[6] Kamal, P. (2014) Summary of Cyanidin. https://examine.com/supplements/cyanidin

[7] Malvidin-3-Glucoside. https://pubchem.ncbi.nlm.nih.gov/compound/malvidin-3-glucoside

[8] Top 4 Types of Anthocyanins. http://www.biologydiscussion.com/plants/secondary-metabolites/top-4-types-of-an thocyanins-anthocyanins/25272

[9] Peonidin-3-Glucoside. https://pubchem.ncbi.nlm.nih.gov/compound/443654

[10] Annie Price, CHHC (2019). https://draxe.com/black-rice-nutrition-forbidden-rice-benefits

[11] Arshiya, S. (2019). https://www.stylecraze.com/articles/health-benefits-of-black-rice/\#gref

[12] Jillian, L. (2018) 10 Powerful Zinc Benefits, Including Fighting Cancer. https://draxe.com/zinc-benefits

[13] Chaffee, B.W. and King, J.C. (2012) Effect of Zinc Supplementation on Pregnancy and Infant Outcomes: A Systematic Review. Paediatric and Perinatal Epidemiology, 26, 118-137. https://www.ncbi.nlm.nih.gov/pubmed/22742606 https://doi.org/10.1111/j.1365-3016.2012.01289.x

[14] Wakeel, A., Farooq, M., Bashir, K. and Ozturk, L. (2018) Micronutrient Malnutrition and Biofortification: Recent Advances and Future Perspectives. In: Hossain, M.A., Kamiya, T., Burritt, D.J., Tran, L.P. and Fujiwara, T., Eds., Plant Micronutrient Use Efficiency, Academic Press, Cambridge, 225-243.

[15] Saeed, A. (2013) Zinc Status in South Asian Populations-An Update. Journal of Health, Population and Nutrition, 31, 139-149.

https://doi.org/10.3329/jhpn.v31i2.16378

[16] Tamanna, B., Kavita, M., Manika, K., Ram, P. and Ajit, V. (2015) Biosynthesis of Zinc Oxide Nanoparticles from Azadirachta indica for Antibacterial and Photocatalytic Applications. Material Science in Semiconductor Processing, 32, 55-61. https://doi.org/10.1016/j.mssp.2014.12.053

[17] Tamanna, B.M.K., Rishabh, S., Patel, S., Reddy, R., Anand, S. and Ajit, V. (2015) A Comparative Study of Pure and Copper $(\mathrm{Cu})$-Doped $\mathrm{ZnO}$-Nanorods for Antibacterial and Photocatalytic Applications with Their Mechanism of Action. Journal of Nanoparticle Research, 17, 288. https://doi.org/10.1007/s11051-015-3093-3

[18] Rishabh, S., Uma, S.S., Ajit, V. and Manika, K. (2016) Visible Light Induced Bactericidal and Photocatalytic Activity of Hydrothermally Synthesized $\mathrm{BiVO}_{4} \mathrm{Na}-$ no-Octahedrals. Journal of Photochemistry \& Photobiology B: Biology, 162, 266-272. https://doi.org/10.1016/j.jphotobiol.2016.06.035 
[19] Rishabh, S., Manika, K., Islam, S., Uma, S. and Ajit, V. (2017) Aspect Ratio Dependent Photo Induced Antimicrobial and Photocatalyticorganic Pollutant Degradation Efficiency of ZnO-Nanorods. Research on Chemical Intermediates, 43, 5345-5364. https://doi.org/10.1007/s11164-017-2930-7

[20] Hilbert, M., Voll, L.M., Hofmann, J. and Zuccaro, A. (2013) Growth Assay and Detection of TRP and Indole Derivatives in Piriformospora indica Culture Supernatant by LC-MS/MS. Bio-Protocol, 3, e800. https://doi.org/10.21769/BioProtoc.800

[21] Uma, S., Manika, K., Ram, P. and Ajit, V. (2017) Impact of Synergistic Association of ZnO-Nanorods and Symbiotic Fungus Piriformospora indica DSM 11827 on Brassica oleracea var. botrytis (Broccoli). Frontiers in Microbiology, 8, 1909.

[22] Uma, A.K.M., Manika, K. and Ajit, V. (2018) Zinc Oxide Nanorods for Fungus Productivity and Broccoli (Brassica oleracea var. botrytis) Development. International Classification, Patent No. 201611027833A.

[23] Ajit, V., Vinod, K., Suman and Ram, P. (2015) A Nanomaterial Based Culture Medium for Microbial Growth Enhancement. India Patent No. 267958.

[24] Pérez-de-Luque, A. (2017). https://www.frontiersin.org/articles/10.3389/fenvs.2017.00012/full\#h1

[25] Terekhova, V., et al. (2017) Engineered Nanomaterials Effects on Soil Properties: Problems and Advances in Investigation. In: Ghorbanpour, M., Manika, K. and Varma, A., Eds., Nanoscience and Plant-Soil Systems, Springer, Berlin, Vol. 48, 115-136

[26] Sridhar, C. (2012) Effect of Nanoparticles for the Maintenance of Tomato Seed Vigour and Viability. M.Sc. Thesis, Tamil Nadu Agricultural University, Coimbatore.

[27] Nair, R.S.H., et al. (2010) Nanoparticulate Material Delivery to Plants. Plant Science, 179, 154-163.

[28] Anandaraj, K. and Natarajan, N. (2017) Effect of Nanoparticles for Seed Quality Enhancement in Onion [Allium cepa (Linn) cv. CO (On)]5. International Journal of Current Microbiology and Applied Sciences, 6, 3714-3724. https://doi.org/10.20546/ijcmas.2017.611.435

[29] Maryam, H., Zahra, A. and Mozafarian, M. (2012) The Effect of N-Si on Tomato Seed Germination under Salinity Levels. Journal of Biodiversity and Environmental Sciences, 6, 87-90.

[30] Bhuyan, S.K., et al. (2015) Interaction of Piriformospora indica with Azotobacter chroococcum. Scientific Reports, 5, Article No. 13911.

[31] Ajit, V., Janardhanan, R., Kharkwal, H., et al. (2019) Novel Rice Based Fortified Food Targeting Micro- and Macro-Nutritional Deficiencies in Malnourished Children and Women.

[32] Savita, V., et al. (1998) Piriformospora indica, gen. etsp. nov., a New Root-Colonizing Fungus. Mycologia USA, 90, 896-903. https://doi.org/10.1080/00275514.1998.12026983

[33] Michael, W., et al. (2016) Sebacinales-One Thousand and One Interactions with Land plants. New Phytologist, 211, 20-40. https://doi.org/10.1111/nph.13977 